\title{
Remodeling of the Lymphatic Vasculature during Mouse Mammary Gland Morphogenesis Is Mediated via Epithelial-Derived Lymphangiogenic Stimuli
}

\author{
Kelly L. Betterman, ${ }^{* \dagger}$ Sophie Paquet-Fifield, ${ }^{\ddagger}$ \\ Marie-Liesse Asselin-Labat, ${ }^{\S}$ Jane E. Visvader, ${ }^{\S \uparrow}$ \\ Lisa M. Butler, ${ }^{\dagger}{ }^{\dagger}$ Steven A. Stacker, ${ }^{\ddagger * *}$ \\ Marc G. Achen, ${ }^{\ddagger \star *}$ and Natasha L. Harvey ${ }^{\star \dagger}$ \\ From the Division of Haematology, " Centre for Cancer Biology, \\ SA Pathology and the Dame Roma Mitchell Cancer Research \\ Laboratories," Hanson Institute, SA Pathology, Adelaide; the \\ Discipline of Medicine, ${ }^{\dagger}$ University of Adelaide, Adelaide; the \\ Peter MacCallum Cancer Centre, ${ }^{\ddagger}$ East Melbourne; the Walter \\ and Eliza Hall Institute of Medical Research, ${ }^{\S}$ Parkville; and the \\ Sir Peter MacCallum Department of Oncology, ${ }^{* *}$ University of \\ Melbourne, ${ }^{\text {"I }}$ Parkville, Australia
}

Despite the key roles of lymphatic vessels in homeostasis and disease, the cellular sources of signals that direct lymphatic vascular growth and patterning remain unknown. Using high-resolution imaging in two and three dimensions, we demonstrated that postnatal mouse mammary gland lymphatic vessels share an intimate spatial association with epithelial ducts and large blood vessels. We further demonstrated that the lymphatic vasculature is remodeled together with the mammary epithelial tree and blood vasculature during postnatal mouse mammary gland morphogenesis. Neither estrogen receptor $\alpha$ nor progesterone receptor were detected in lymphatic endothelial cells in the mouse mammary gland, suggesting that mammary gland lymphangiogenesis is not likely regulated directly by these steroid hormones. Epithelial cells, especially myoepithelial cells, were determined to be a rich source of prolymphangiogenic stimuli including VEGF-C and VEGF-D with temporally regulated expression levels during mammary gland morphogenesis. Blockade of VEGFR-3 signaling using a small-molecule inhibitor inhibited the proliferation of primary lymphatic endothelial cells promoted by mammary gland conditioned medium, suggesting that lymphangiogenesis in the mammary gland is likely driven by myoepithelial-derived VEGF-C and/or VEGF-D. These findings provide new insight into the architecture of the lymphatic vasculature in the mouse mammary gland and, by uncovering the proximity of lymphatic vessels to the epithelial tree, suggest a potential mechanism by which metastatic tumor cells access the lymphatic vasculature. (Am J Pathol 2012, 181:2225-2238; http://dx.doi.org/10.1016/j.ajpath.2012.08.035)

The lymphatic vasculature fulfils key physiological functions during development and homeostasis; these include the return of interstitial protein-rich fluid to the bloodstream, absorption of dietary fats and fat-soluble vitamins from the digestive tract, and trafficking of immune cells during surveillance and inflammation. ${ }^{1,2}$ Construction of the lymphatic vasculature begins during embryogenesis upon specification of a population of lymphatic endothelial progenitor cells in the embryonic cardinal veins. ${ }^{3}$ These cells exit the veins to form lymph sacs and a primitive lymphatic plexus that is progressively remodeled to generate a hierarchical vascular network comprised of initial lymphatic vessels, the site at which fluid is absorbed, and collecting lymphatics that propel lymph back to the bloodstream. ${ }^{1,2}$ The initial phase of lymphatic endothelial cell (LEC) migration away from the cardinal veins is dependent on the vascular endothelial growth factor (VEGF) family member VEGF-C, ${ }^{4}$ although the cellular sources of VEGF-C important for this process have not been definitively determined. The identity of signals that guide LEC migration and patterning of the lymphatic vasculature during development also re-

Supported by the National Breast Cancer Foundation (doctoral research scholarship to K.B.), the National Health and Medical Research Council of Australia (M.A., N.H., S.S., J.V.), the Cancer Council of South Australia (N.H., L.B.), Victorian Breast Cancer Research Consortium (J.V.), and a fellowship from MedVet Pty Ltd (N.H.).

Accepted for publication August 30, 2012.

Disclosures: S.A.S. and M.G.A. are consultants and shareholders of Vegenics, Ltd., a company developing antiangiogenic and antilymphangiogenic therapeutics.

Supplemental material for this article can be found at http://ajp. amjpathol.org or at $h$ ttp://dx.doi.org/10.1016/j.ajpath.2012.08.035.

Address reprint requests to Natasha Harvey, Ph.D., Division of Haematology, Centre for Cancer Biology, SA Pathology, P.O. Box 14, Rundle Mall, Adelaide, SA 5000, Australia. E-mail: natasha.harvey@health.sa. gov.au. 
main to be determined, although recent work in zebrafish suggests that both arteries ${ }^{5}$ and motoneurons ${ }^{6}$ may provide important directive cues.

The lymphatic vasculature remains relatively quiescent in adults, with the exception of hormone-mediated remodeling in the ovary ${ }^{7}$ and in settings of tissue repair and inflammation, in which the growth of new lymphatic vessels (lymphangiogenesis) is promoted. ${ }^{1,8}$ In inflammatory settings including the tumor microenvironment, the production of growth factors including VEGF-C and VEGF-D by either tumor cells or cells of the immune system, induces lymphangiogenesis, an event that correlates with metastasis in both mouse tumor models ${ }^{9-14}$ and human cancer. ${ }^{15-19}$ Metastasis may also be aided via the effects of VEGF-C and VEGF-D on collecting lymphatic vessels; VEGF-C and VEGF-D promote the dilation of collecting lymphatic vessels and elevate lymph flow, factors that facilitate the transport of metastatic cells to sentinel lymph nodes. ${ }^{1,20}$ Although the lymphatic vasculature has long been recognized as an important route for tumor metastasis, and for breast cancer metastasis in particular, ${ }^{16,21,22}$ the mechanisms by which tumor cells access lymphatic vessels are still not well understood.

Normal mammary tissue undergoes dramatic morphological changes in response to hormonal signals and functional demands during postnatal mouse mammary gland morphogenesis; this cycle begins at puberty and encompasses both the estrous cycle ${ }^{23,24}$ and the adult female reproductive cycle of pregnancy, lactation, and involution. ${ }^{25,26}$ These remodeling events are not restricted to the mammary epithelial tree; the blood vasculature also undergoes repeated cycles of angiogenic expansion during pregnancy and lactation, followed by regression during involution. ${ }^{27-29}$ VEGF, the major driver of angiogenesis, is produced by both epithelial and stromal cells in the mammary gland, ${ }^{29}$ and blood vascular growth and remodeling progresses normally during pregnancy in mice in which the Vegf gene is conditionally inactivated in epithelial cells, although vascular density and vascular permeability are reduced during lactation. ${ }^{30}$ These data suggest that stromal cells in the mammary gland constitute an important source of VEGF, or that proangiogenic factors in addition to VEGF are important for mammary gland angiogenesis. Although it is well established that the epithelial tree and blood vasculature are intimately associated and coordinately remodeled during postnatal mouse mammary gland morphogenesis, the architecture of the lymphatic vasculature in the mouse mammary gland is relatively uncharted. Given the importance of the lymphatic vasculature for breast cancer metastasis, we sought to uncover the spatial organization of lymphatic vessels in the mouse mammary gland, to determine whether the lymphatic vasculature, like the blood vasculature, is remodeled during mammary gland morphogenesis, and to investigate the identity and source of signals that control lymphangiogenesis in this tissue. To our knowledge, the present study represents the first specific analysis of lymphatic ves- sel growth and remodeling during postnatal mammary gland morphogenesis in the mouse.

\section{Materials and Methods}

\section{Animal Studies}

C57BL/6 mice were used for experiments involving wildtype mice. Adult female mice were subjected to timed pregnancies and were scored by the presence of vaginal plugs, with the day of vaginal plug detection designated as 0.5 days post coitum. Inguinal (fourth pair) mammary glands were used for all immunostaining and cell isolation purposes. All animal procedures were approved by and conducted in accordance with the SA Pathology/ $\mathrm{CHN}$ Animal Ethics Committee, the University of Adelaide Animal Ethics Committee, the Walter and Eliza Hall Institute (WEHI) Animal Ethics Committee, the Peter MacCallum Cancer Centre Animal Experimental Ethics Committee, and the Australian National Health and Medical Research Council guidelines. Mice carrying a floxed Gata-3 allele and cre-recombinase expressed under the control of the mouse mammary tumor virus (MMTV) promoter (referred to as MMTV-creD; Gata-3) and mice expressing the oncoprotein polyoma middle $T$ antigen (PyMT) under the control of MMTV (denoted MMTV-PYMT) have been described previously. ${ }^{31,32}$ Vegfd-deficient mice (denoted Vegfd $^{-1-}$ ) have been described previously. ${ }^{33}$

\section{Antibodies, Staining Procedures, and Image Acquisition}

Primary antibodies used for immunofluorescent immunostaining were rabbit anti-Prox1 (AngioBio, Del Mar, CA), rat anti-mouse CD31 (BioLegend, San Diego, CA), goat anti-mouse E-cadherin (R\&D Systems, Minneapolis, MN), goat anti-mouse CCL21 (R\&D Systems), Cy3-conjugated mouse monoclonal anti- $\alpha$-smooth muscle actin (SigmaAldrich, St. Louis, MO), goat anti-mouse VEGFR-3 (R\&D Systems), hamster anti-mouse podoplanin (clone 8.1.1; Developmental Studies Hybridoma Bank, lowa City, IA), rabbit anti-ER $\alpha$ (MC-20; Santa Cruz Biotechnology, Santa Cruz, CA), rabbit anti-human progesterone receptor (DakoCytomation, Glostrup, Denmark), rabbit anti-keratin 14 (Covance, Princeton, NJ), rat anti-mouse PDGFR- $\beta$ (eBioscience, San Diego, CA), rabbit anti-mouse LYVE-1 (AngioBio), and rat anti-mouse CD45 (BD Pharmingen, San Diego, CA). AlexaFluor fluorochrome-conjugated secondary antibodies (Invitrogen; Life Technologies, Carlsbad, CA) were used for signal detection.

For immunofluorescent immunostaining of cryosections, inguinal mammary glands (see Supplemental Figure $\mathrm{S} 1$ at $h t t p: / / a j p . a m j p a t h o l . o r g$ ) were fixed overnight at $4^{\circ} \mathrm{C}$ using $4 \%(\mathrm{w} / \mathrm{v})$ paraformaldehyde in PBS, followed by cryopreservation in 30\% (w/v) sucrose/PBS. Glands were embedded into Tissue-Tek OCT optimal cutting temperature compound (Sakura Finetek, Zoeterwoude, Netherlands) and cryosectioned in a transverse orientation at a thickness of $45 \mu \mathrm{m}$. Immunostaining was per- 
formed as described previously. ${ }^{34}$ The $z$-stack images were obtained using a Radiance 2100 confocal microscope (Bio-Rad Laboratories, Hercules, CA) equipped with three lasers (argon gas-ion, $488 \mathrm{~nm}$; HeNe green, $543 \mathrm{~nm}$; and red diode, $637 \mathrm{~nm}$ ) attached to an Olympus IX70 inverted microscope with UPlanApo 10×/0.40 $\infty / 0.17$ and UApo/340 20×/0.70W $\infty / 0.17$ objectives (Olympus, Tokyo, Japan). Image acquisition was performed at room temperature using Bio-Rad LaserSharp 2000 software version 5.2 (Bio-Rad Laboratories). Photoshop CS5 software version 12.0 (Adobe Systems, San Jose, CA) was used for subsequent image processing.

For whole-mount immunofluorescent immunostaining, inguinal mammary glands were fixed as described above, permeabilized in PBS containing $0.3 \%(\mathrm{v} / \mathrm{v})$ Triton $\mathrm{X}-100$ (PBS-0.3\% TX), and blocked overnight at $4^{\circ} \mathrm{C}$ in PBS-0.3\% TX containing 1\% (w/v) bovine serum albumin. Glands were incubated overnight with primary antibodies diluted in blocking solution at $4^{\circ} \mathrm{C}$ with gentle agitation, washed extensively (5 washes, 1 hour each) on ice using PBS- $0.3 \% \mathrm{TX}$, and incubated overnight at $4^{\circ} \mathrm{C}$ with respective AlexaFluor fluorochrome-conjugated secondary antibodies (Life Technologies) (diluted in blocking solution). Samples were washed extensively overnight in PBS- $0.3 \%$ TX, before postfixation in $4 \%(\mathrm{w} / \mathrm{v})$ paraformaldehyde and dehydration using a graded methanol series. A 1:2 mix of benzyl alcohol:benzyl benzoate was used for clearing and mounting the glands in uncoated Petri dishes ( $\mu$-Dish ${ }^{35} \mathrm{~mm}$, low; ibidi, Martinsried, Germany). Zstack image acquisition through the entire thickness of the mammary fat pads was performed as described above. A three-dimensional reconstruction of a $z$-stack taken through a whole-mount immunostained mammary gland was generated by Chris Johnson (PerkinElmer, Melbourne), using Volocity 3D Image Analysis software version 6.1.1 (PerkinElmer, Waltham, MA).

For analysis of steroid hormone receptor expression, inguinal mammary glands were fixed overnight in neutralbuffered formaldehyde (10\% (v/v) formalin solution), processed using a Tissue-Tek VIP vacuum infiltration tissue processor (Sakura Finetek), and paraffin-embedded. Transverse sections (4 $\mu \mathrm{m}$ thick) were dewaxed and rehydrated before heat-mediated antigen retrieval in citrate buffer ( $\mathrm{pH}$ 6.5). Paraffin-embedded sections were blocked using PBS containing 0.3\% (v/v) Tween 20 (Sigma-Aldrich) and $1 \%(\mathrm{w} / \mathrm{v})$ bovine serum albumin and were incubated with primary antibodies overnight at $4^{\circ} \mathrm{C}$. Sections were washed extensively using PBS and incubated with AlexaFluor fluorochrome-conjugated secondary antibodies (Life Technologies) for 2 hours. Samples were mounted in Gel Mount aqueous mounting medium with antifading agents (Biomeda, Foster City, CA). Images were captured at room temperature using an Olympus DP-70 camera attached to an Olympus BX51 microscope with an UPlanApo $20 \times / 0.70 \infty / 0.17$ objective (Olympus) and were processed using OLYSIA BioReport software version 3.2 (Olympus) and Adobe Photoshop CS5 software version 12.0 .

For immunofluorescent immunostaining of inguinal mammary gland cell culture monolayers, cells grown in ibiTreat tissue culture-treated $\mu$-Slide 8-well slides (ibidi) were fixed in $4 \%(\mathrm{w} / \mathrm{V})$ paraformaldehyde and permeabilized using PBS containing $0.1 \%(v / v)$ Triton X-100 (PBS$0.1 \% \mathrm{TX}$ ), followed by blocking for 30 minutes in PBS$0.1 \%$ TX containing $0.2 \%(\mathrm{w} / \mathrm{v})$ bovine serum albumin and overnight incubation with primary antibodies (diluted in blocking solution). Cells were washed three times (10 minutes for each wash) in PBS-0.1\% TX, before incubation for 3 hours with AlexaFluor fluorochrome-conjugated secondary antibodies (Life Technologies) (diluted in PBS-0.1\% TX). Samples were washed and mounted in ProLong Gold antifade reagent with DAPI (Life Technologies). Images were collected at room temperature using a Nikon C1-Z confocal microscope equipped with three solid-state lasers (488 nm, sapphire; $532 \mathrm{~nm}$ and $405 \mathrm{~nm}$, Compass) attached to a Nikon Eclipse TE2000 inverted microscope with a Plan Apo 20×/0.75 Ph2 DM $\infty / 0.17$ WD 1.0 objective (Nikon, Tokyo, Japan). Images were processed using EZ-C1 FreeViewer Gold software version 3.90 (Nikon) and Adobe Photoshop CS5 software version 12.0.

Inguinal mammary glands for whole-mount carmine alum staining were fixed in Carnoy's solution [60\% (v/v), ethanol, 30\% (v/v), chloroform, and 10\% (v/v) glacial acetic acid] for 4 hours, rehydrated using a graded ethanol series, and stained overnight in carmine alum [0.2\% (w/v) carmine (Sigma-Aldrich) and 0.5\% (w/v) aluminum potassium sulfate]. Glands were dehydrated through a graded ethanol series and cleared overnight in xylene. Samples were mounted in DePeX mounting medium (BDH Laboratory Supplies, Poole, UK) and analyzed at room temperature using an Olympus SZX7 stereo microscope and DF PLAPO 1X-4 objective, equipped with an Olympus DP20-5E digital camera. Images were acquired using DP20-DRV software version 1.1 (Olympus) and processed using Adobe Photoshop CS5 software version 12.0.

\section{Mammary Gland Cell Isolation, Labeling, and Sorting}

Left and right inguinal mammary fat pads (see Supplemental Figure S1 at http://ajp.amjpathol.org) were dissected from 16.5-day pregnant mice ( $n=2$ to 4$)$, and single-cell suspensions were prepared as described previously. ${ }^{35}$ Immediately after isolation, Fc receptors were blocked for 30 minutes on ice using $50 \mu \mathrm{g}$ per $10^{6}$ cells of mouse $\gamma$-globulin (Jackson ImmunoResearch Laboratories, West Grove, PA). Cells were labeled using PE/Cy7 rat anti-mouse CD31 (BioLegend), PE/Cy5 rat anti-mouse CD24 (BioLegend), AlexaFluor 647 rat anti-mouse CD45 (BioLegend), and AlexaFluor 647 rat anti-mouse F4/80 (Life Technologies), each at a concentration of $0.25 \mu \mathrm{g}$ per $10^{6}$ cells, in combination with AlexaFluor 700 hamster anti-mouse/rat CD29 (BioLegend) at $0.5 \mu \mathrm{g}$ per $10^{6}$ cells. Unbound antibodies were removed by washing twice with Hanks' balanced salt solution containing $10 \mathrm{mmol} / \mathrm{L}$ HEPES and $5 \%(v / v)$ fetal bovine serum (SAFC Biosciences, Lenexa, KS). Labeled cells were sorted on a FACSAria flow cytometer (BD Biosciences, San Jose, CA), and data analysis was performed on the live cell gate 
using FACSDiVa software version 6.1.3 (BD Biosciences). Mammary epithelial cells were gated to exclude any cell positive for CD31, CD45, or F4/80 and then were subjected to positive selection using CD24 and differential expression of CD29 (luminal epithelial cells CD24positive/CD29low; myoepithelial cells CD24-positive/ CD29 high) as described previously. ${ }^{35}$ Fractionated cells were collected into microcentrifuge tubes containing PBS supplemented with $50 \%(\mathrm{v} / \mathrm{v})$ fetal bovine serum (SAFC Biosciences). The purity of isolated mammary gland cell populations was assessed by real-time quantitative RTPCR (qPCR) (see Supplemental Figure S2 at $h$ ttp://ajp. amjpathol.org), as described below.

Mammary gland cell suspensions were generated from inguinal mammary glands ( $n=2$ to 4 for each morphogenetic time point per independent experiment), excluding the central lymph node. Glands were digested for 50 minutes at $37^{\circ} \mathrm{C}$ in Dulbecco's modified Eagle's medium (Sigma-Aldrich) supplemented with $5 \%(\mathrm{v} / \mathrm{v})$ fetal bovine serum (SAFC Biosciences), $150 \mathrm{U} / \mathrm{mL}$ of both collagenase type 1 and collagenase type 3 (Worthington Biochemical, Lakewood, NJ), and $100 \mathrm{U} / \mathrm{mL}$ hyaluronidase (Worthington Biochemical).

\section{RNA Analysis}

Total RNA was isolated from whole inguinal mammary gland cell suspensions using TRIzol reagent (Life Technologies) or from FACS cellular fractions using an Ambion RNAqueous-Micro microscale RNA isolation kit (Life Technologies) according to the respective manufacturer's instructions. For investigation of mRNA, total RNA was reverse transcribed using SuperScript III first-strand synthesis supermix (Life Technologies) combined with a mixture of oligo(dT) 20 and random hexamer primers. qPCR was performed in triplicate using $\mathrm{RT}^{2}$ real-time SYBR Green/Rox master mix (Qiagen, Hilden, Germany) and a Corbett Research RotorGene 6000 real-time rotary analyzer (Qiagen). Primers (Table 1) were designed with the aid of Primer3 software version 4.0. ${ }^{36}$ Data were collected and analyzed using Rotor-Gene 6000 series software version 1.7
(Qiagen). All data were normalized to Actb (encoding $\beta$-actin) as described previously. ${ }^{37}$

\section{Cell Culture and ex Vivo Proliferation Assays}

Inguinal mammary gland cell cultures were grown in Dulbecco's modified Eagle's medium (Sigma-Aldrich) supplemented with $10 \%(\mathrm{v} / \mathrm{v})$ fetal bovine serum (SAFC Biosciences), $50 \mathrm{U} / \mathrm{mL}$ penicillin (Gibco, Paisley, UK), and $50 \mu \mathrm{g} / \mathrm{mL}$ streptomycin (Gibco) at $37^{\circ} \mathrm{C} / 5 \% \mathrm{CO}_{2}$. To generate mammary gland conditioned medium (CM), mammary gland cell suspensions were seeded into $25-\mathrm{cm}^{2}$ tissue culture flasks for 6 hours. The CM was collected (CM1), and viable adherent cells were rinsed with culture medium and grown for a further 72 hours. Cells were then passaged and cultured for an additional 96 hours, before collection of a second batch of CM (CM2). The CM was centrifuged to pellet cellular debris, syringe-filtered through a $0.2-\mu \mathrm{m}$ sterile filter, and stored in aliquots at $-70^{\circ} \mathrm{C}$.

Primary mouse LECs were isolated from E16.5 mouse dermis as described previously. ${ }^{38}$ All ex vivo proliferation assays were performed using LECs seeded at a density of $1 \times 10^{4}$ cells per well in 96-well microplates coated with $50 \mu \mathrm{g} / \mathrm{mL}$ fibronectin (Roche, Mannheim, Germany), with three or four replicates for each treatment group. Freshly isolated LECs were cultured overnight at $37^{\circ} \mathrm{C} / 5 \% \mathrm{CO}_{2}$ in endothelial cell basal medium-2 (EBM-2; Lonza, Walkersville, MO) supplemented with microvascular endothelial cell growth medium-2 (EGM-2-MV) SingleQuots (Lonza), and then were serum-starved for 4 hours in EBM-2 (Lonza) supplemented with $0.5 \mathrm{mg} / \mathrm{mL}$ Gibco AlbuMAX I lipid-rich bovine serum albumin (Life Technologies). Control and treatment groups were added to LECs, and cell proliferation was assessed after 48 hours using CellTiter $96 \mathrm{AQ}_{\text {ueous }}$ One Solution cell proliferation assay reagent (Promega, Madison, WI), according to the manufacturer's instructions. Absorbances at $490 \mathrm{~nm}$ were measured on a FLUOstar OPTIMA microplate reader (BMG LABTECH, Offenburg, Germany). Treatment groups consisted of EBM-2 (Lonza) supplemented with $30 \%(\mathrm{v} / \mathrm{v})$ mammary gland $\mathrm{CM}$, whereas

Table 1. Primer Pairs Used for $q P C R$ Analysis

\begin{tabular}{|c|c|c|}
\hline Gene & Forward primer & Reverse primer \\
\hline Acta2 & 5'-GCATCCACGAAACCACCTAT-3' & 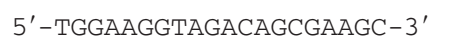 \\
\hline Actb & $5^{\prime}$-GATCATTGCTCCTCCTGAGC-3' & $5^{\prime}$-GTCATAGTCCGCCTAGAAGCAT-3' \\
\hline Angpt1 & $5^{\prime}$-CAGCATCTGGAGCATGTGAT- $3^{\prime}$ & $5^{\prime}$-AACATCTGTCAGCTTTCGGG-3' \\
\hline Angpt2 & $5^{\prime}$-GATCTTCCTCCAGCCCCTAC-3' & $5^{\prime}$-CAGCAAGCTGGTTCCAATCT-3' \\
\hline Fgf1 & 5'-AGCCCAAACTGCTCTACTGC-3' & 5'-GGTTTTCTTCCAGCCTTTCC-3' \\
\hline Fgf2 & $5^{\prime}$-AGCGGCTCTACTGCAAGAAC-3' & $5^{\prime}$-GCCGTCCATCTTCCTTCATA-3' \\
\hline Hgf & $5^{\prime}-\mathrm{TGCCAGAAAGATATCCCGAC-3^{ \prime }}$ & 5'-CTTCTCCTTGGCCTTGAATG-3' \\
\hline Krt18 & $5^{\prime}$-CCTTGCCGCCGATGACTTTA-3' & $5^{\prime}$-CAGCCTTGTGATGTTGGTGT-3' \\
\hline Pdgfa & $5^{\prime}$-GAGATACCCCGGGAGTTGAT- $3^{\prime}$ & $5^{\prime}-$ TCTTGCAAACTGCAGGAATG- $3^{\prime}$ \\
\hline Pdgfb & $5^{\prime}-$-CCTCGGCCTGTGACTAGAAG- $3^{\prime}$ & $5^{\prime}$-GGGGCAATACAGCAAATACC- $3^{\prime}$ \\
\hline Pecam1 & $5^{\prime}$-AACAGAAACCCGTGGAGATG- $3^{\prime}$ & 5'-GTCTCTGTGGCTCTCGTTCC-3' \\
\hline Ptprc & 5'-GGGTTGTTCTGTGCCTTGTT-3' & $5^{\prime}$-GGATAGATGCTGGCGATGAT-3' \\
\hline Vegfa & $5^{\prime}-$ TGAGACCCTGGTGGACATCT-3' & 5'-TATGTGCTGGCTTTGGTGAG- $3^{\prime}$ \\
\hline Vegfc & $5^{\prime}-$ GCAGCTAACAAGACATGTCCAA-3' & $5^{\prime}-\mathrm{CCACAACTAGATGGCCGAAG-3^{ \prime }}$ \\
\hline Vegfd & 5'-TGCAAGACGAGACTCCACTG-3' & 5'-GCAGCAGCTCTCCAGACTTT-3' \\
\hline
\end{tabular}


control LECs were grown in EBM-2 (Lonza) supplemented with $30 \%(\mathrm{v} / \mathrm{v})$ of unstimulated mammary gland cell culture medium. Two small-molecule tyrosine kinase inhibitors were used: MAZ51 (5 $\mu \mathrm{mol} / \mathrm{L}$; Sigma-Aldrich) ${ }^{39,40}$ and SU5416 (5 $\mu \mathrm{mol} / \mathrm{L}$; Sigma-Aldrich), ${ }^{41}$ previously demonstrated to inhibit VEGF-C-mediated LEC proliferation. ${ }^{42}$ The final concentration of dimethyl sulfoxide was consistent across all control and treatment groups at $0.2 \%(\mathrm{v} / \mathrm{v})$.

\section{Quantification and Statistical Analysis}

Lymphatic vessels were counted in six to eight frozen transverse sections of mammary tissue from mammary glands harvested from three mice for each morphogenetic time point or genotype. Lymphatic vessel density (LVD) was calculated by dividing lymphatic vessel counts from each section by the corresponding section area $\left(\mathrm{cm}^{2}\right)$, as determined using ImageJ software version $1.41\left(\mathrm{NIH}\right.$, Bethesda, MD). ${ }^{43}$

Data analysis was performed at the Data Management and Analysis Centre (University of Adelaide, Adelaide, Australia) using SAS software version 9.2 (SAS Institute, Cary, NC). A mixed-model approach, analogous to analysis of variance, was used for statistical analysis of lymphatic vessel density. If a significant difference between postnatal stages was detected $(P<0.05)$, pair-wise comparison using a Šidák adjustment for multiple comparisons was used to determine differences between means. For ex vivo LEC proliferation assays with multiple treatments, data were analyzed using analysis of variance, assuming a randomized complete block design, with at least three data points obtained for each condition. If a significant difference between treatments was detected at the $5 \%$ significance level $(P<0.05)$, then pair-wise comparisons using a Šidák adjustment for multiple comparisons was used to determine differences between means. Alternatively, a one-way analysis of variance was used for the statistical analysis of lymphangiogenic growth factor expression at the mRNA level in multiple postnatal stages of mammary gland development. If a significant difference between postnatal stages was detected $(P<0.05)$, then pair-wise comparisons using a Tukey's multiple comparison test was performed to determine differences between means. For all other statistical analyses, $P$ values were calculated using the twotailed Student's t-test.

\section{Results}

\section{Lymphatic Vessels Are Intimately Associated with Epithelial Ducts and Large Blood Vessels in the Postnatal Mouse Mammary Gland}

To ascertain the spatial location of lymphatic vessels within the mouse mammary gland parenchyma, immunofluorescent staining of cryopreserved tissue sections (45 $\mu \mathrm{m}$ thick) was performed using a combination of CD31 (a pan-endothelial cell marker), Prox1 (a marker of LEC identity), and E-cadherin (a marker of epithelial cell iden- tity) antibodies. Lymphatic vessels were observed in close proximity to mammary ducts and large blood vessels (Figure 1) at all morphogenetic stages analyzed, suggesting that signals derived from ductal epithelial cells and/or the blood vasculature may provide cues that govern lymphatic vessel patterning in the mammary gland.

On the basis of morphology, the lymphatic vessels running in parallel with large blood vessels resembled large-caliber collecting lymphatic vessels (Figure 1). The spatial relationship between lymphatic vessels and epithelial ducts was further confirmed in both virgin and pregnant stages on whole-mount immunostaining of mammary glands (Figure 2), an approach that enabled a superior three-dimensional view of the spatial organization of the lymphatic vasculature. Lymphatic vessels were observed to track alongside and spiral around mammary ducts (Figure 2; see also Supplemental Video S1 at $h t t p: / /$ ajp.amjpathol.org), in a manner similar to the way blood vessels run in parallel or encircle the mammary ducts in the virgin gland. ${ }^{28}$ Intriguingly, lymphatic vessels were not observed in the vicinity of the alveoli during pregnancy (Figure 2, F and $\mathrm{H}$ ), unlike the well-characterized blood-vascular capillary baskets that elaborately encapsulate alveoli (Figure 2G; see also Supplemental Video S1 at $h$ ttp://ajp.amjpathol.org). ${ }^{27,28}$ Lymphatic vessels traversed along minor ductal side branches but did not extend into alveolar clusters (Figure 2H; see also Supplemental Video S1 at http://ajp.amjpathol.org). Taken together, these observations suggest that spatially restricted pro- and antilymphangiogenic signals may be responsible for the confinement of lymphatic vessels to epithelial ducts.

In addition to prominent Prox 1 staining in the lymphatic vasculature of postnatal mouse mammary glands, Prox 1 was also apparent in discrete regions of the blood vasculature, at levels similar to those observed in lymphatic vessels (see Supplemental Figure S3 at http://ajp. amjpathol.org). Costaining with Prox1 and VEGFR-3 to distinguish lymphatic vessels from blood vessels, combined with analysis of vessel morphology and the documented restriction of intraluminal valves to veins, ${ }^{44}$ corroborated the identity of these blood vessels as veins (see Supplemental Figure S3, D-L, at http://ajp. amjpathol.org). Prox1 has recently been shown to be present at high levels in lymphatic, ${ }^{45,46}$ venous $^{47}$ and lymphovenous valves, ${ }^{48}$ and Prox 1 is required for the formation of lymphovenous valves. ${ }^{48}$ Interestingly, Prox 1 positive venous valves appeared morphologically distinct from their lymphatic counterparts, appearing as small clusters of Prox1-positive cells, rather than as bicuspid valve leaflets (see Supplemental Figure S3, A-C, at $h t t p: / /$ ajp.amjpathol.org), and were located exclusively at sites of venous bifurcation (see Supplemental Figure S3, D-L, at $h t t p: / / a j p . a m j p a t h o l . o r g)$. Although Prox1 localization in valves of mouse iliac veins and human saphenous veins has recently been documented, ${ }^{47}$ to our knowledge this is the first demonstration that Prox 1 is present in venous valves of the mouse mammary gland. 

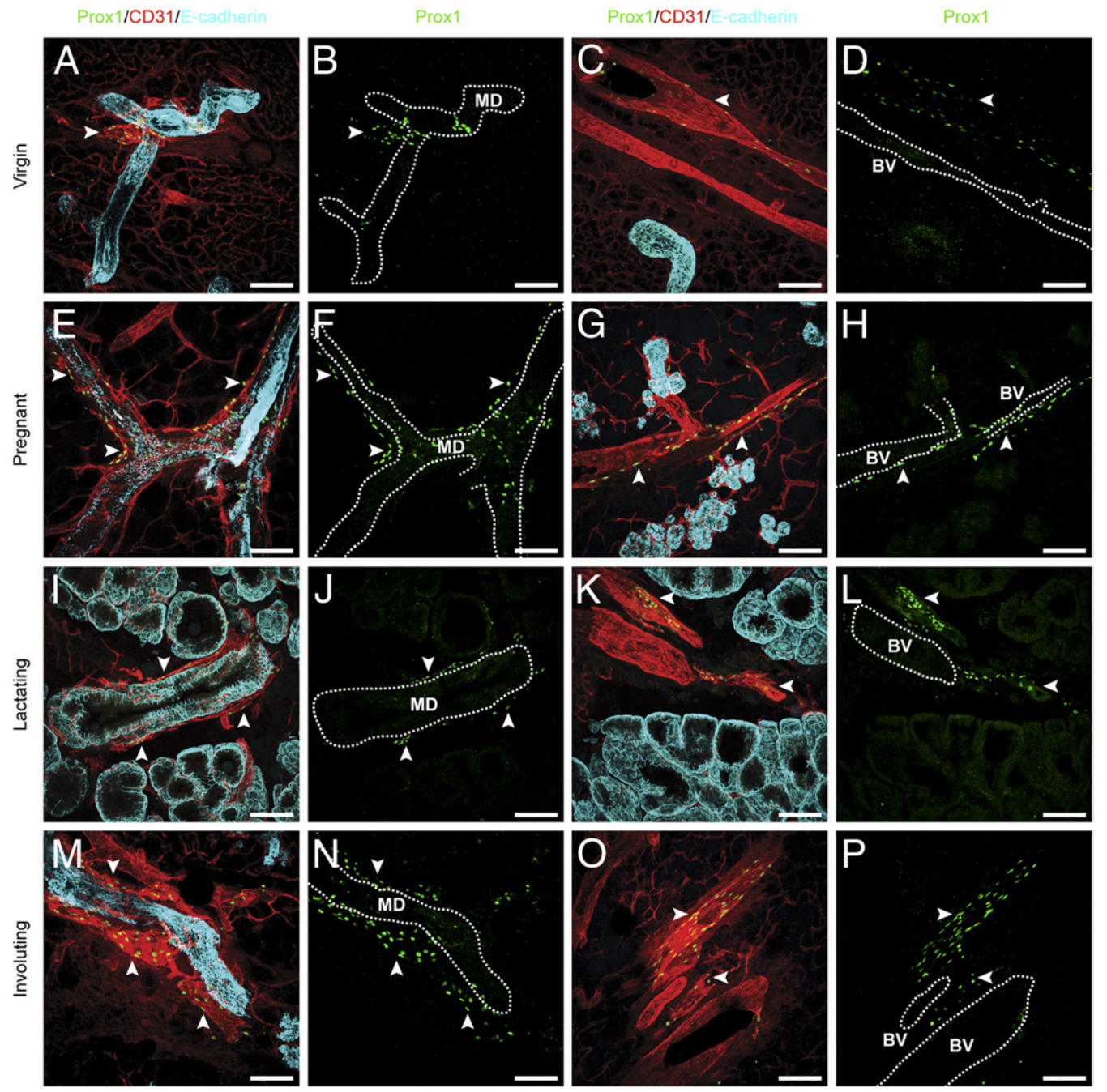

Figure 1. Lymphatic vessels are intimately associated with epithelial ducts and large blood vessels in the postnatal mouse mammary gland. Lymphatic vessels (arrowheads) are spatially associated with mammary ducts (MD) (A, B, E, F, I, J, M, and $\mathbf{N})$ and large blood vessels (BV) $(\mathbf{C}, \mathbf{D}, \mathbf{G}, \mathbf{H}, \mathbf{K}, \mathbf{L}, \mathbf{O}$, and $\mathbf{P})$. Immunofluorescent staining in 8-week virgin (A-D), 14.5-day pregnant (E-H), 10-day lactating (I-L), and 11-day involuting (M-P) wild-type mouse mammary gland tissue sections for Prox1 (green; lymphatic vessels), CD31 (red; blood and lymphatic vessels), and E-cadherin (cyan; mammary epithelial cells). Dashed lines demarcate the peripheral margins of mammary ducts and blood vessels. Single-channel confocal $z$-stack images in $\mathbf{B}, \mathbf{D}, \mathbf{F}, \mathbf{H}, \mathbf{J}, \mathbf{L}, \mathbf{N}$, and $\mathbf{P}$ correspond to images in $\mathbf{A}, \mathbf{C}, \mathbf{E}, \mathbf{G}, \mathbf{I}, \mathbf{K}, \mathbf{M}$, and $\mathbf{O}$, respectively. Images are representative of three mice per morphogenetic stage. Scale bar $=100 \mu \mathrm{m}$.

\section{The Lymphatic Vasculature Is Remodeled during Postnatal Mammary Gland Morphogenesis}

To investigate whether the lymphatic vasculature is remodeled during mammary gland morphogenesis, lymphatic vessel density was quantified in inguinal mammary glands of wild-type C57BL/6 female mice across multiple stages of the reproductive cycle. Lymphatic vessels, identified as Prox1-positive, CD31-positive vessels (Figure 1) in $45-\mu \mathrm{m}$ transverse sections of virgin, pregnant, lactating, and involuting mammary glands were counted and normalized to section area using ImageJ software version $1.41 .{ }^{43}$ These analyses revealed that the mammary gland lymphatic vascular network undergoes dramatic expansion during pregnancy (LVD $=18$ vessels/ $\mathrm{cm}^{2}$ in pregnancy, compared with 8 vessels $/ \mathrm{cm}^{2}$ in virgin glands; $P<0.05$ ), followed by regression after preg- nancy to a virgin-like state (LVD $=6$ vessels $/ \mathrm{cm}^{2} ; P<$ 0.001) (Figure 3). A similar dynamic pattern of expansion and regression of the blood microvasculature across the reproductive cycle in the postnatal mouse mammary gland has been documented previously, with a similar peak in blood vascular capillary density observed during pregnancy. ${ }^{27-29}$

\section{Lymphatic Vessel Density in the Postnatal Mouse Mammary Gland Correlates with Density of the Epithelial Tree}

Based on our observations of elevated LVD during pregnancy, which is a period of extensive epithelial expansion, ${ }^{25}$ and the observation that lymphatic vessels shared an intimate spatial association with mammary ducts, we hypothesized that the mammary epithelial tree might pro- 
$\mathrm{CCL} 21 / \alpha \mathrm{SMA} /$
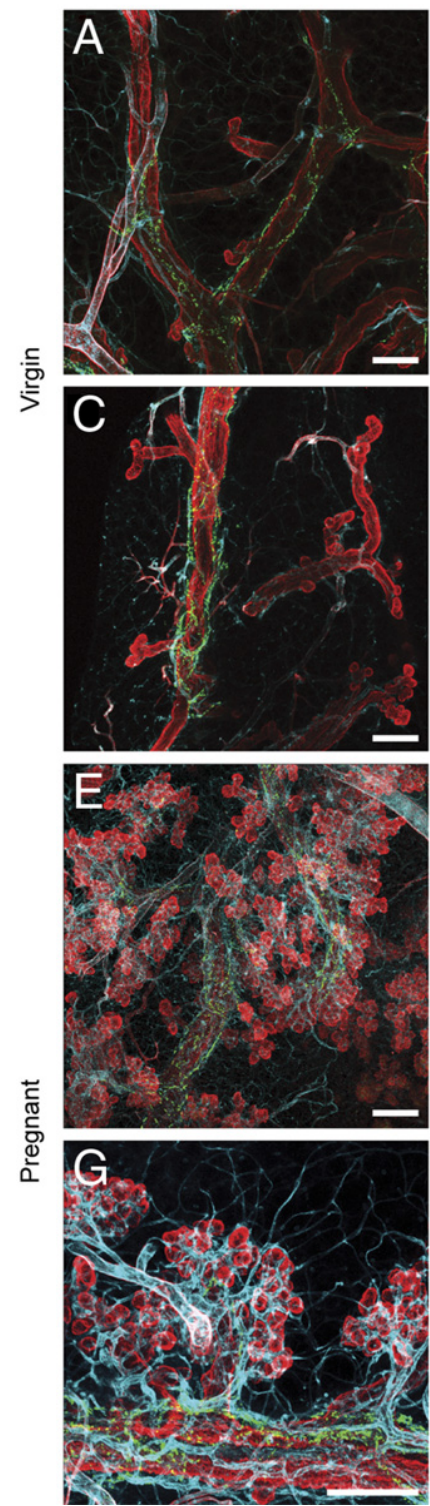

Figure 2. Lymphatic vessels share an intimate spatial association with mouse mammary ducts, but not alveoli. Whole-mount immunofluorescent staining in 8-week virgin (A-D) and 14.5-day pregnant (E-H) mouse mammary glands for CCL21 (green; lymphatic vessels), $\alpha$-SMA (red; vascular smooth muscle and myoepithelial cells), and CD31 (cyan; blood and lymphatic vessels). Lymphatic vessels (arrowheads) track alongside and spiral around mammary ducts (d) $(\mathbf{B}, \mathbf{D}, \mathbf{F}$, and $\mathbf{H})$, but do not infiltrate alveolar clusters (al) (arrow; $\mathbf{F}$ and $\mathbf{H}$ ). Two-channel confocal $z$-stack images in $\mathbf{B}, \mathbf{D}$ $\mathbf{F}$, and $\mathbf{H}$ correspond to images in $\mathbf{A}, \mathbf{C}, \mathbf{E}$, and $\mathbf{G}$, respectively. Images are representative of two mice per morphogenetic stage. Scale bar $=150 \mu \mathrm{m}$.

vide an important source of lymphangiogenic growth and/or patterning factors. To address this possibility, LVD was investigated in inguinal mammary glands harvested from MMTV-PyMT mice, ${ }^{32,49}$ which exhibit a hyperplastic epithelial tree. LVD was dramatically elevated (25 vessels $\left./ \mathrm{cm}^{2}\right)$ in the MMTV-PyMT mice, compared with wildtype counterparts (8 vessels $\left./ \mathrm{cm}^{2}\right)(P<0.01, n=3)$ (Figure 4). Preliminary analysis of LVD in mammary glands from MMTV-cre ${ }^{T /+}$; Gata-3/f ${ }^{f / f}$ ice, which showed limited expansion of the ductal tree compared with control littermates, ${ }^{31}$ revealed a trend toward reduced LVD
$\left(L V D=4\right.$ vessels $/ \mathrm{cm}^{2}$, compared with 8 vessels $/ \mathrm{cm}^{2}$ in control littermates; data not shown). Taken together, these data reveal a strong correlation between density of the epithelial tree and lymphatic vessel density in the mouse mammary gland and suggest that mammary gland epithelia are a potential source of prolymphangiogenic stimuli.

\section{LECs in the Mouse Mammary Gland Lack Detectable Expression of ER $\alpha$ and PR}

It is well established that the growth and development of the mammary gland epithelial compartment is dependent on and is coordinated by a complex interplay among the ovarian steroid hormones estrogen and progesterone and the pituitary hormone prolactin, along with a multitude of local growth factors. ${ }^{50-52}$ In the mammary gland, estrogen and progesterone have been shown to regulate ductal $^{53}$ and alveolar morphogenesis, ${ }^{50}$ respectively, through interaction with their cognate nuclear receptors [estrogen receptor $\alpha(E R \alpha)$, estrogen receptor $\beta(E R \beta)$, and progesterone receptor (PR)]. Given the importance of estrogen and progesterone in remodeling of the postnatal mammary epithelial tree, we sought to determine whether estrogen and progesterone directly regulate remodeling of the mammary lymphatic vasculature. To this end, we investigated the localization of ER $\alpha$ and PR in the postnatal mouse mammary gland. Although both of these nuclear hormone receptors were evident in mammary epithelial cells, neither ER $\alpha$ nor PR were detected in LECs at any morphogenetic stage analyzed (Figure 5). These observations suggest that lymphatic vessels in the mammary gland are unlikely to respond directly to estrogen and progesterone (although indirect mechanisms cannot be excluded).

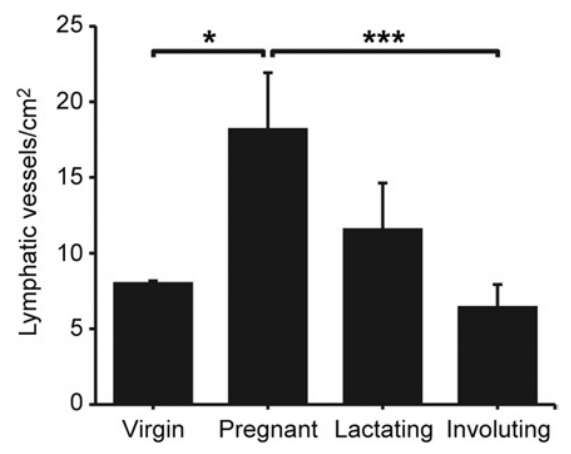

Figure 3. Lymphatic vessels are remodeled during mouse mammary gland morphogenesis. Peak lymphatic vessel density in the postnatal mouse mammary gland is achieved during pregnancy. Lymphatic vessel quantification was performed in mammary glands harvested from 8-week virgin, 14.5-day pregnant, 10-day lactating, and 11-day involuting mice. Data are expressed as means \pm SEM. ${ }^{*} P<0.05$, ${ }^{\text {***** } P}<0.001$, Šidák adjustment for multiple comparisons; mixed modeling approach. $n=3$ mice per developmental stage. 

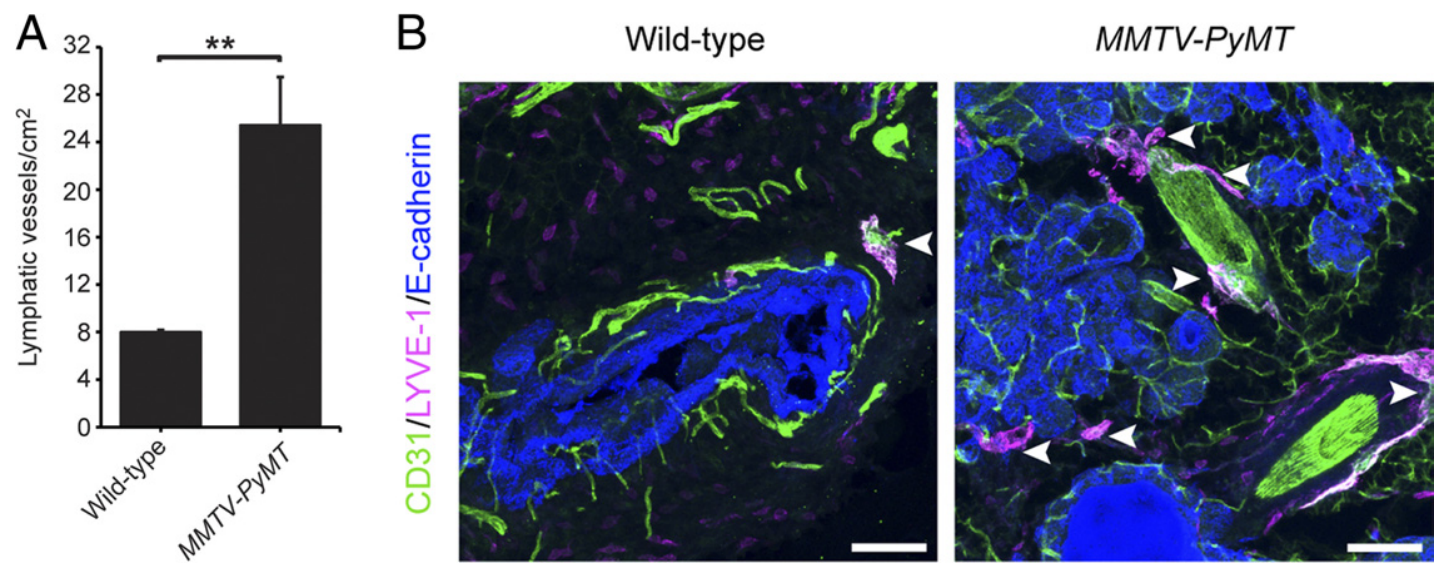

Figure 4. Lymphatic vessel density correlates with density of the epithelial tree in the postnatal mouse mammary gland. A: Quantification of mammary gland lymphatic vessel density in 8-week-old wild-type and $M M T V-P y M T$ mice reveals increased lymphatic vessel density in $M M T V$-PyMT mice. B: Immunofluorescent staining for CD31 (green), LYVE-1 (magenta), and E-cadherin (blue) reveals density of lymphatic vessels (arrowheads) in 8-week-old wild-type and $M M T V-P y M T$ mammary glands. Data are expressed as means \pm SEM. ${ }^{* *} P<0.01$, two-tailed Student's $t$-test. $n=3$. Scale bar $=100 \mu$ m.

\section{Prolymphangiogenic Growth Factor Expression Is Temporally Regulated during Postnatal Mouse Mammary Gland Morphogenesis}

To investigate the identity of lymphangiogenic stimuli responsible for the dynamic regulation of lymphatic vessel growth and remodeling in the mouse mammary gland, we assessed the expression of established prolymphangiogenic growth factors in cell suspensions prepared from 9-week virgin, early pregnant (4.5 day), and late-stage pregnant (16.5 day) wild-type mammary glands, using qPCR. A striking increase in Vegfc and Vegfd expression was observed in 4.5-day pregnant mammary glands, relative to both virgin and late pregnant stages (Figure 6A); Vegfc levels at day 4.5 of pregnancy were elevated approximately 15-fold and Vegfd levels ninefold, compared with virgin glands. These data correlate with our observation that peak lymphatic vessel density is achieved during pregnancy (Figure 3). By day 16.5 of pregnancy, Vegfc and Vegfd mRNA levels had returned to levels below those observed in virgin glands (Figure 6A). In contrast, the expression of Vegfa was not markedly altered at the mRNA level during pregnancy (Figure 6A), negating a global effect in gene regulation across the VEGF family. Similarly, transiently elevated expression of Pdgfa (approximately fourfold) and Hgf (approximately 2.5-fold) was observed at day 4.5 of pregnancy, suggesting that these growth factors may also contribute to expansion of the lymphatic vasculature during pregnancy (Figure 6B).

As a means of further defining the cellular sources of lymphangiogenic stimuli in the mouse mammary gland, enriched populations of luminal, myoepithelial, and hematopoietic cells were isolated using FACS from 16.5day pregnant wild-type mice (see Supplemental Figure S2 at http://ajp.amjpathol.org). Quantification of established prolymphangiogenic growth factor mRNA levels using qPCR revealed that expression of the Vegfc, Vegfd, Pdgfa, Pdgfb, Fgf1, and Hgf genes was elevated in myoepithelial cells, relative to luminal epithelial and hematopoietic cells (Figure 6C). Enriched expression of prolymphangiogenic growth factors in the myoepithelial cell compartment is in accord with our observation that lymphatic vessels are intimately associated with mammary epithelial ducts, which are bilayered epithelial structures encased by contractile myoepithelial cells. ${ }^{54}$ Collectively, our data suggest that the growth and patterning of lymphatic vessels in the postnatal mouse mammary gland is likely to be regulated by epithelial-derived prolymphangiogenic growth factors and that myoepithelial cells are a rich source of these factors.

\section{Mammary Epithelial-Derived Growth Factors Promote LEC Proliferation in Vitro}

To define paracrine prolymphangiogenic growth factors produced in the pregnant mouse mammary gland, primary dermal $\mathrm{LECs}^{38}$ were cultured with CM collected from mammary gland cell suspension cultures isolated from pregnant mice. The CM was harvested at two time points: at 6 hours after the initial seeding of mammary gland cell suspensions (CM1) and at 96 hours after the first passage of adherent cells (CM2). A 1.8-fold increase in LEC proliferation was observed when LECs were cultured with $\mathrm{CM} 1$, relative to control medium, but LEC proliferation was not promoted by CM2 (Figure 7A). To assess whether the cellular composition of mammary gland cultures changed over time in culture, mammary gland cultures were immunostained at the time points at which CM was collected, using a battery of markers characteristic of epithelial, hematopoietic, and fibroblast identity. At the time of CM1 collection, large sheets of flat, densely packed, cuboidal epithelial cells predominated (Figure 7C); however, after passage (corresponding to the collection of CM2), only small clusters of epithelial cells remained (Figure 7F). Immunostaining using cytokeratin 14 (K14), a marker of myoepithelial identity, ${ }^{52}$ revealed that the majority of epithelial cells in culture were myoepithelial (Figure 7, C and F). Staining for platelet-derived growth factor receptor $\beta$ (PDGFR- $\beta$ ) and $\alpha$-SMA confirmed that fibroblasts were present in both mammary gland cell passages (Figure 7, D and G) and that they 
Podoplanin/ER $\alpha$
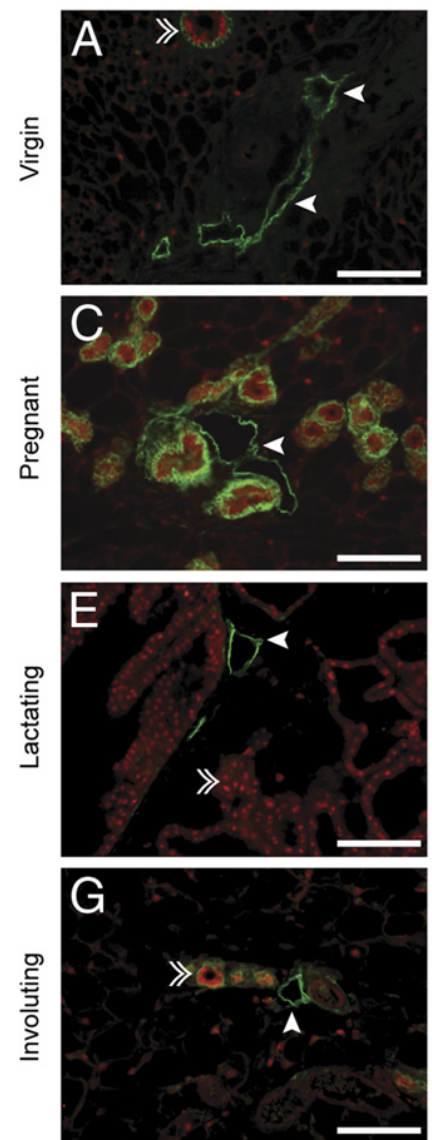

Figure 5. Estrogen receptor $\alpha$ and progesterone receptor are not detected in the mouse mammary gland lymphatic vasculature. Immunofluorescent staining of 6-week virgin (A and B), 16.5-day pregnant (C and D), 10-day lactating $(\mathbf{E}$ and $\mathbf{F})$, and 10-day involuting $(\mathbf{G}$ and $\mathbf{H})$ wild-type mouse mammary gland tissue sections for podoplanin (green) and estrogen receptor $\alpha(\mathrm{ER} \alpha)$ (red; $\mathbf{A}$ $\mathbf{C}, \mathbf{E}$, and $\mathbf{G}$ ) or progesterone receptor (PR; red; $\mathbf{B}, \mathbf{D}, \mathbf{F}$, and $\mathbf{H})$. Epithelial expression (double arrowheads) of $\mathrm{ER} \alpha$ and $\mathrm{PR}$ is evident, but lymphatic vessels (arrowheads) lack detectable expression of $\mathrm{ER} \alpha$ and PR. Images are representative of two mice per morphogenetic stage. Scale bar $=100 \mu \mathrm{m}$.

represented the major cell type in culture after passage (Figure 7G). Given the increase in $\alpha$-SMA expression, these cells are likely to be activated fibroblasts. ${ }^{55}$ The number of CD45-positive hematopoietic cells, including macrophages, appeared similar between CM1 and CM2 cell suspensions from which CM was collected (Figure 7 , $\mathrm{E}$ and $\mathrm{H}$ ). Taken together, these data illustrate that mammary gland epithelial cells, and most likely myoepithelial cells, represent the predominant cellular source of soluble prolymphangiogenic growth factors present in mammary gland $\mathrm{CM}$.

As a means of further delineating the growth factors and signaling pathways responsible for mammary gland CM-stimulated LEC proliferation, the ability of small-molecule tyrosine kinase inhibitors to inhibit CM1-promoted LEC proliferation was investigated. Given our finding that mRNAs encoding VEGF-C and VEGF-D were elevated early during pregnancy (Figure 6A), we assessed both MAZ51, reported to selectively block VEGF-C and VEGFD-induced phosphorylation of VEGFR-3, ${ }^{39,40}$ and SU5416, a potent and selective inhibitor of VEGFR-2. ${ }^{41}$
MAZ51 potently inhibited CM1-induced LEC proliferation, but SU5416 had negligible effects (Figure 7B). These data suggest that signaling via VEGFR-3, but not VEGFR-2, mediates mammary gland CM-induced LEC proliferation ex vivo and implicate VEGF-C and VEGF-D as prolymphangiogenic stimuli in the pregnant mouse mammary gland.

\section{Vegfd Is Dispensable for Lymphangiogenesis during Postnatal Mouse Mammary Gland Morphogenesis}

Because inactivation of the Vegfc gene results in defective lymphatic vascular development and embryonic lethality in mice, ${ }^{4}$ we focused our attention on determining whether Vegfd is required for postnatal mammary gland lymphangiogenesis. Given that Northern blot analyses of adult rat tissues have demonstrated that Vegfd mRNA is most highly expressed in branched epithelial organs, including the mammary gland, ${ }^{39}$ we first investigated whether Vegfd deficiency had any discernible effect on the epithelial architecture in the mouse mammary gland. Whole-mount carmine alum staining demonstrated that the epithelial architecture was similar between Vegfd $^{+/+}$ and $\mathrm{Vegfd}^{-/-}$pregnant mice (see Supplemental Figure S4 at http://ajp.amjpathol.org). Lymphatic vascular patterning and remodeling was then analyzed in virgin and pregnant mammary glands isolated from Vegfd $^{-/-}$ mice, ${ }^{33}$ using whole-mount immunofluorescent immunostaining. These analyses revealed that lymphatic vessel patterning in the mammary gland was indistinguishable between $\mathrm{Vegfd}^{+/+}$and $\mathrm{Vegfd^{-/- }}$ mice at virgin and pregnant stages (Figure 8). Lymphatic vessels were intimately spatially associated with mammary ducts in Vegfd $^{-/-}$ mammary glands (Figure 8, D and $\mathrm{H}$ ). Taken together, these data illustrate that Vegfd is dispensable for epithelial branching morphogenesis and for the growth and patterning of lymphatic vessels in the postnatal mouse mammary gland.

\section{Discussion}

The present study documents the first specific analysis of lymphangiogenesis during postnatal mammary gland morphogenesis in the mouse. High-resolution imaging in two and three dimensions revealed that lymphatic vessels share an intimate spatial association with epithelial ducts and large blood vessels in the mouse mammary gland. Lymphatic vessels were observed to encircle epithelial ducts in virgin and pregnant mammary glands; in contrast to the blood vasculature, however, these vessels were not dispersed throughout the mammary gland adipose tissue and were excluded from alveoli during pregnancy. Large collecting lymphatic vessels were found to run in parallel with large arteries and veins. Moreover, we determined that the lymphatic vasculature is remodeled along with the epithelial tree and blood vasculature during puberty, pregnancy, lactation, and involution. Myoepithelial cells were found to be a rich source of prolymphangiogenic growth factors, including VEGF-C and 
A

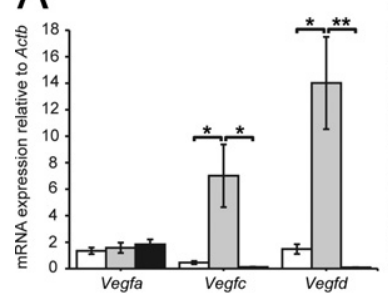

B

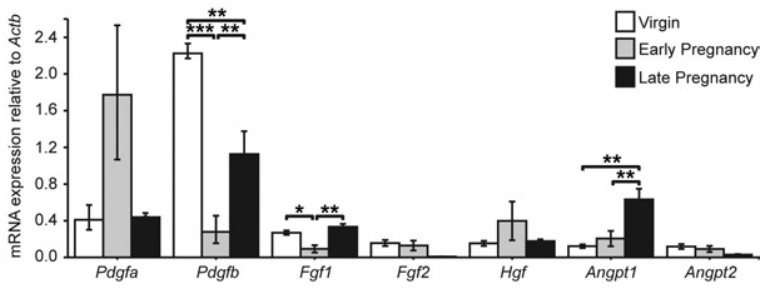

C

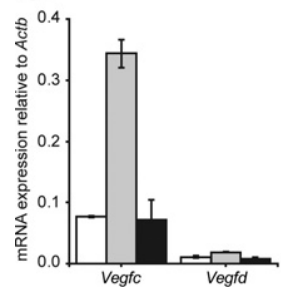

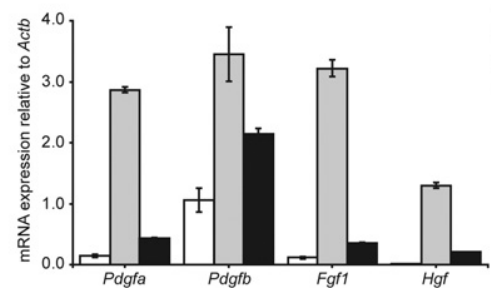

Figure 6. mRNA expression of prolymphangiogenic growth factors is temporally regulated during mouse mammary gland morphogenesis. A and B: QPCR analysis of prolymphangiogenic growth factor expression in mammary glands harvested from 9-week virgin compared with early ( 4.5 day) and late ( 16.5 day) pregnant mice. C: QPCR analysis of prolymphangiogenic growth factor expression in mammary gland epithelial and hematopoietic cells FACS-isolated from 16.5-day pregnant mouse mammary glands demonstrate that expression of prolymphangiogenic growth factors is elevated in myoepithelial cells. Data are expressed as means \pm SEM of at least three independent experiments, with each individual experiment comprising samples pooled from at least two mice per morphogenetic stage (A and $\mathbf{B})$ or as means \pm $\mathrm{SD}$ of replicate samples from one experiment, comprising samples pooled from two mice (ie, four inguinal mammary glands) $(\mathbf{C}) .{ }^{*} P<0.05$ ${ }^{* *} P<0.01$, and ${ }^{* * * *} P<0.001$, one-way analysis of variance; Tukey's test for multiple comparisons.
VEGF-D. Expression of these factors was temporally regulated during mammary gland morphogenesis; peak mRNA levels were observed at an early stage of pregnancy, corresponding to the stage at which the lymphatic vasculature peaked in density. These data, together with our observation that signaling via VEGFR-3 mediated the proliferation of LECs promoted by mammary epithelial cell-derived CM, strongly implicate VEGF-C and VEGF-D as key prolymphangiogenic growth factors in the mouse mammary gland.

Our finding that lymphatic vessels in the mouse mammary gland are closely associated with epithelial ducts and large blood vessels concurs with an earlier study performed in the rat mammary gland by Ohtani et $\mathrm{al}^{56}$
A

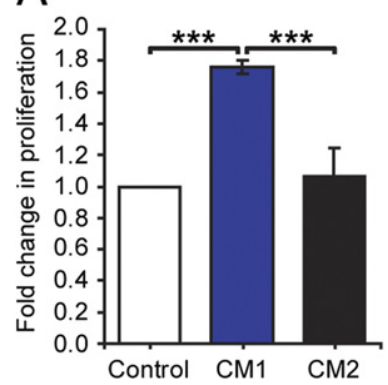

E-cadherin/K14/DAPI
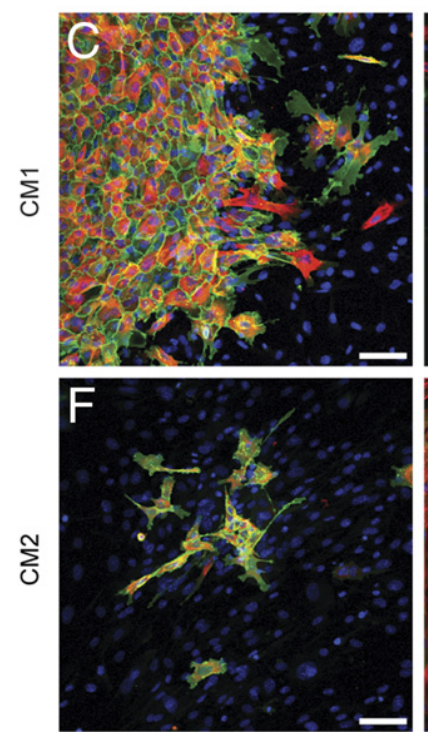

$\mathrm{B}$

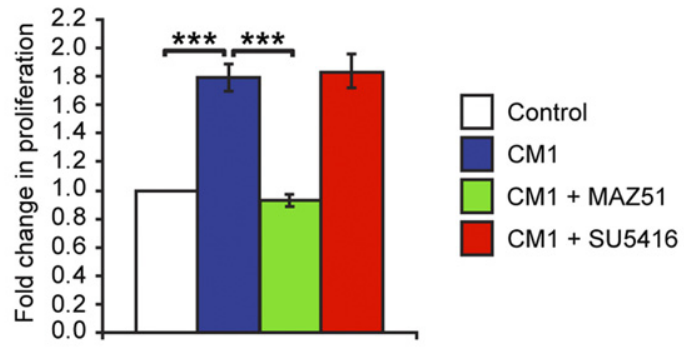

PDGFR $\beta / \alpha$ SMA/DAPI
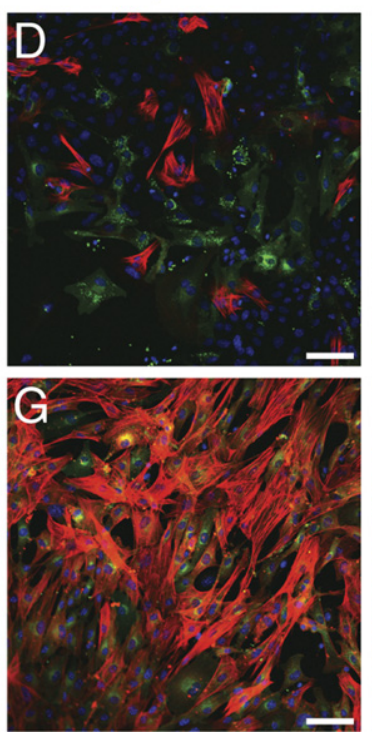

CD45/ $\alpha$ SMA/DAPI
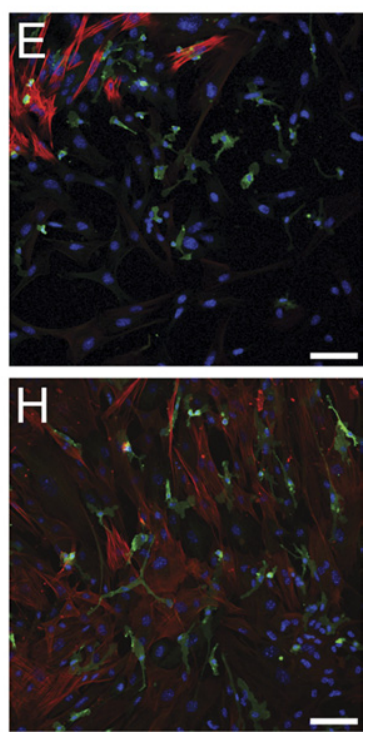

Figure 7. Mouse mammary gland CM promotes LEC proliferation ex vivo via VEGFR-3. A: CM (30\% $\mathrm{v} / \mathrm{v})$ collected from 16.5-day pregnant mammary gland cell cultures at passage 0 (CM1), but not passage 1 (CM2), results in increased LEC proliferation. LEC proliferation was assessed 48 hours after the addition of CM using CellTiter 96 AQueous One Solution cell proliferation assay reagent (Promega). B: Primary dermal LECs were cultured for 48 hours with or without $30 \%(\mathrm{v} / \mathrm{v})$ mammary gland CM1, together with the small-molecule tyrosine kinase inhibitor MAZ51 $(5 \mu \mathrm{mol} / \mathrm{L}$ VEGFR-3) or SU5416 ( $5 \mu \mathrm{mol} / \mathrm{L}$; VEGFR-2). C-H: Immunofluorescent staining of passage $0(\mathbf{C}-\mathbf{E})$ and passage $1(\mathbf{F}-\mathbf{H})$ mammary gland cell culture monolayers demonstrated that epithelial cells constitute the major cell type before passage. DAPI was used as a nuclear counterstain. Data are expressed as means \pm SEM of three independen experiments, encompassing three independent LEC isolations and three independent batches of CM. ${ }^{* * * *} P<0.0001$, analysis of variance; Šidák adjustment for multiple comparisons. Scale bar $=$ $100 \mu \mathrm{m}$ 

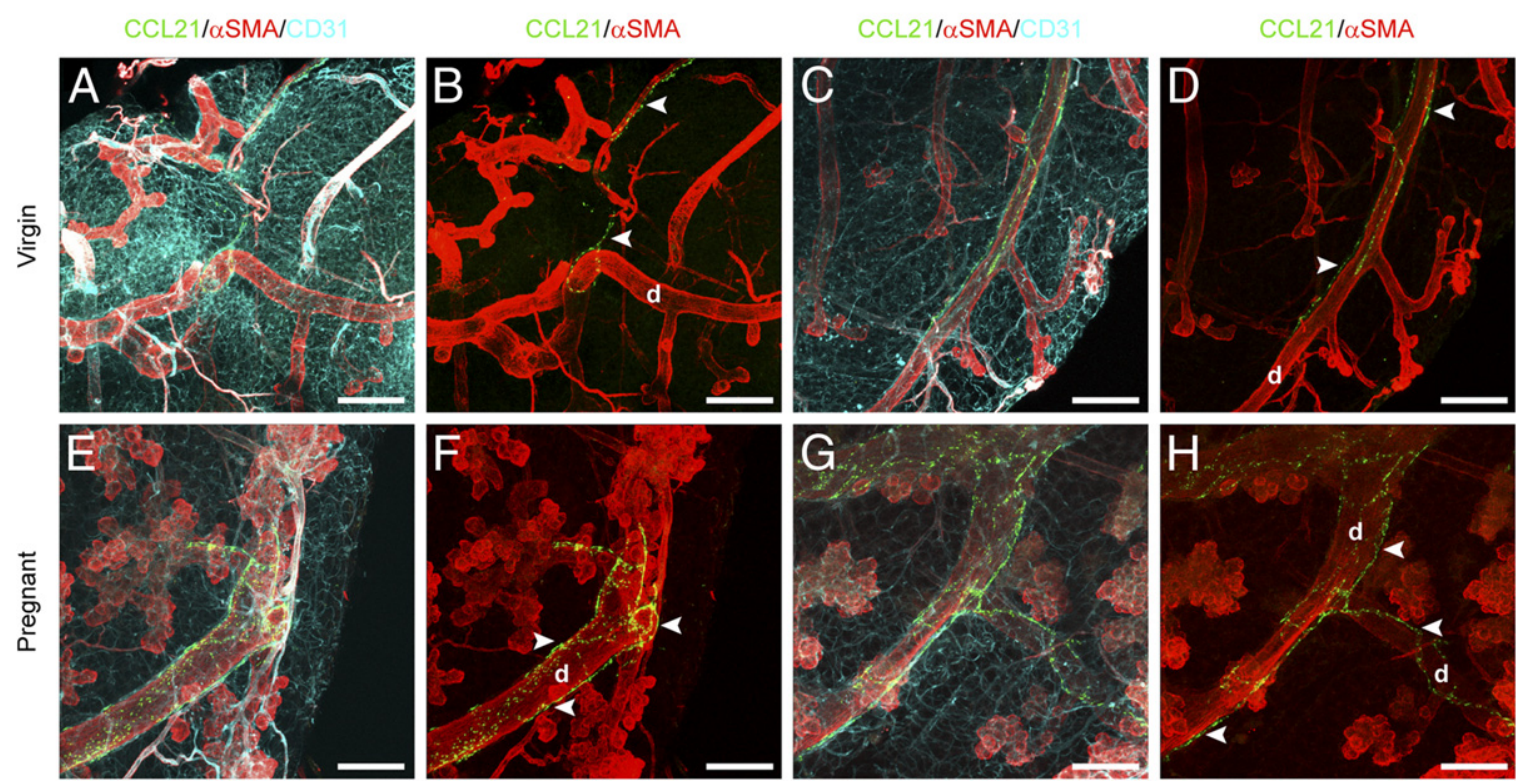

Figure 8. Vegfd is dispensable for mouse mammary gland lymphangiogenesis. Whole-mount immunofluorescent staining of virgin (A-D) and 14.5-day pregnant $(\mathbf{E}-\mathbf{H}) \mathrm{Vegfd}^{+/+}(\mathbf{A}, \mathbf{B}, \mathbf{E}$, and $\mathbf{F})$ and $\operatorname{Vegfd}^{-1}(\mathbf{C}, \mathbf{D}, \mathbf{G}$, and $\mathbf{H})$ mouse mammary glands for CCL21 (green; lymphatic vessels), $\alpha$ smooth muscle actin $(\alpha-$ SMA; red; vascular smooth muscle and myoepithelial cells) and CD31 (cyan; blood and lymphatic vessels) reveal that lymphatic vessel patterning is indistinguishable between Vegfd $^{+/+}$and Vegfd ${ }^{-/}$mammary glands. Lymphatic vessels (arrowheads) are intimately associated with mammary ducts (d) (B, D, F, and $\mathbf{H}$ ). Two-channel confocal $z$-stack images in $\mathbf{B}, \mathbf{D}, \mathbf{F}$, and $\mathbf{H}$ correspond to images in $\mathbf{A}, \mathbf{C}, \mathbf{E}$, and $\mathbf{G}$, respectively. Images are representative of at least two mice per developmental stage and genotype. Scale bar $=150 \mu \mathrm{m}$.

who used light and transmission electron microscopy techniques to analyze lymphatic vessel localization in tissue sections of rat mammary glands at virgin, pregnant, lactating, and involuting stages. In addition to ductal and blood vascular localization, and in contrast to our work, lymphatic vessels in the rat mammary gland were found throughout interlobular connective tissue and in close association with the alveoli during pregnancy. ${ }^{56}$ Our analysis of lymphatic vessel architecture in wholemouse mammary glands provides a particularly clear view of the organization of the lymphatic vasculature with lymphatic vessel specific markers; neither interlobular nor alveolar associated lymphatic vessels were apparent in the mouse mammary gland at any morphogenetic stage analyzed. This discrepancy could be due to species differences, given the identification of lymphatic vessels on the basis of $5^{\prime}$-nucleotidase expression (reported by Ohtani et $\mathrm{al}^{56}$ to be expressed at high levels in lymphatic vessels and at lower levels in blood vessels and myoepithelial cells), or as a result of limitations in the two-dimensional view afforded by analysis of tissue sections. Our finding that lymphatic vessels are so intimately localized with mammary epithelial ducts may have important implications for breast cancer metastasis. Lymphatic vascular invasion of breast cancer cells is documented to be a significant predictor of poor patient prognosis and disease outcome, based on a strong association with axillary nodal metastasis. ${ }^{16,57-59}$ The proximity of lymphatic vessels to epithelial ducts in the mouse mammary gland could facilitate lymphatic dissemination of metastatic cells. Furthermore, our demonstration that mammary epithelial cells are a source of a variety of prolymphangiogenic growth factors (including Vegfc, Vegfd,
Pdgfa, Fgf1, and Hgf) suggests that deregulated growth of abnormal epithelial cells has the potential to result in increased production of these growth factors, which could in turn drive the growth of new lymphatic vessels and/or exert effects on collecting lymphatic vessels that facilitate tumor cell dissemination.

Intriguingly, we observed that lymphatic vessels were not spatially associated with alveoli in the pregnant and lactating mouse mammary gland, a striking contrast to the wellcharacterized blood vascular capillary baskets that elaborately encapsulate alveoli during these developmental stages. $^{27,28}$ This observation fits with the disparate functions of alveoli and lymphatic vessels. Alveolar epithelial cells are the site of active milk protein and lipid synthesis and secretion in the mammary gland, ${ }^{25}$ whereas a major role of lymphatic vessels is to return interstitial protein-rich fluid back to the bloodstream. ${ }^{1}$ The presence of lymphatic vessels in close proximity to milk-secreting alveoli would more than likely limit the milk supply to suckling young.

What prevents lymphatic vessels from growing in the region of alveoli? One possibility is that the discontinuous sheath of myoepithelial cells ${ }^{25}$ around alveoli fails to provide sufficient prolymphangiogenic stimuli to promote lymphatic vessel growth into this region. Alternatively, the absence of lymphatic vessels may result as a consequence of the secretion of a repulsive cue by alveolar epithelial cells. One such candidate for repelling lymphatic vascular growth is soluble VEGFR-2 (sVEGFR-2). Albuquerque et $\mathrm{al}^{60}$ recently demonstrated that sVEGFR-2 is expressed in epithelial cells of the cornea and is responsible for maintaining the alymphatic state of the cornea by sequestering endogenous VEGF-C. Native sVEGFR-2 exists as a monomer, which (unlike transmem- 
brane VEGFR-2) has a poor avidity for VEGF-A ${ }^{60}$; this could explain the presence of blood vascular capillary baskets but not lymphatic vessels around alveoli.

Our finding that MAZ51 abrogated the proliferation of LECs that was promoted by CM collected from mammary gland cultures suggested that VEGF-C and/or VEGF-D are likely to play key roles in pregnancy stimulated lymphangiogenesis. Analyses of lymphatic vascular growth and patterning in Vegfd ${ }^{-\prime-}$ mice revealed, however, that Vegfd is dispensable for lymphatic vascular growth and remodeling in the mammary gland. This finding is perhaps not surprising, given that VEGF-D is dispensable for physiological lymphangiogenesis. ${ }^{33,61}$ The high level of structural homology ${ }^{62}$ and functional redundancy ${ }^{63}$ between VEGF-C and VEGF-D suggests that VEGF-C may compensate for the loss of VEGF-D and sustain normal growth and patterning of lymphatic vessels in Vegfd ${ }^{-/-}$ mammary glands. Collectively, our data suggest that VEGF-C and VEGF-D are key growth factors driving lymphangiogenesis during pregnancy in the postnatal mouse mammary gland. Elevated expression of VEGF-C and VEGF-D has been associated with increased lymphangiogenesis, elevated lymphatic vascular invasion, increased frequency of lymph node metastasis, and poor prognosis in both mouse tumor models ${ }^{10,20,61}$ and human breast cancer patients. . $^{9,17-19,64-66}$

In conclusion, the present study provides the first threedimensional view of the lymphatic vasculature in the mouse mammary gland, revealing that the lymphatic vasculature shares an intimate spatial relationship with epithelial ducts and large blood vessels. The findings further demonstrate that the lymphatic vasculature is remodeled along with the epithelial tree and blood vasculature during mammary gland morphogenesis and that epithelial cells, particularly myoepithelial cells, are a rich source of prolymphangiogenic growth factors, levels of which are temporally regulated during mammary gland morphogenesis. The present study sheds new light on the mechanisms by which the lymphatic vasculature is patterned during development and suggests that proximity of the lymphatic vasculature to epithelial ducts may contribute to the lymphatic dissemination of metastatic breast tumor cells.

\section{Acknowledgments}

We thank Kelly Wicks and the staff of the SA Pathology Veterinary Services division for animal husbandry as well as members of our laboratory for helpful discussions.

\section{References}

1. Tammela T, Alitalo K: Lymphangiogenesis: molecular mechanisms and future promise. Cell 2010, 140:460-476

2. Schulte-Merker S, Sabine A, Petrova TV: Lymphatic vascular morphogenesis in development, physiology, and disease. J Cell Biol 2011, 193:607-618

3. Wigle JT, Oliver G: Prox1 function is required for the development of the murine lymphatic system. Cell 1999, 98:769-778

4. Karkkainen MJ, Haiko P, Sainio K, Partanen J, Taipale J, Petrova TV, Jeltsch M, Jackson DG, Talikka M, Rauvala H, Betsholtz C, Alitalo K: Vascular endothelial growth factor $\mathrm{C}$ is required for sprouting of the first lymphatic vessels from embryonic veins. Nat Immunol 2004, 5:74-80
5. Geudens I, Herpers R, Hermans K, Segura I, Ruiz de Almodovar C, Bussmann J, De Smet F, Vandevelde W, Hogan BM, Siekmann A, Claes F, Moore JC, Pistocchi AS, Loges S, Mazzone M, Mariggi G, Bruyere F, Cotelli F, Kerjaschki D, Noel A, Foidart JM, Gerhardt H, Ny A, Langenberg T, Lawson ND, Duckers HJ, Schulte-Merker S, Carmeliet P, Dewerchin M: Role of delta-like-4/Notch in the formation and wiring of the lymphatic network in zebrafish. Arterioscler Thromb Vasc Biol 2010, 30:1695-1702

6. Lim AH, Suli A, Yaniv K, Weinstein B, Li DY, Chien CB: Motoneurons are essential for vascular pathfinding [Erratum appeared in Development 2011, 138:4813]. Development 2010, 138:3847-3857

7. Brown HM, Robker RL, Russell DL: Development and hormonal regulation of the ovarian lymphatic vasculature. Endocrinology 2010, 151:5446-5455

8. Alitalo K: The lymphatic vasculature in disease. Nat Med 2011, 17 : 1371-1380

9. Skobe M, Hawighorst T, Jackson DG, Prevo R, Janes L, Velasco P, Riccardi L, Alitalo K, Claffey K, Detmar M: Induction of tumor lymphangiogenesis by VEGF-C promotes breast cancer metastasis. Nat Med 2001, 7:192-198

10. Stacker SA, Caesar C, Baldwin ME, Thornton GE, Williams RA, Prevo R, Jackson DG, Nishikawa S, Kubo H, Achen MG: VEGF-D promotes the metastatic spread of tumor cells via the lymphatics. Nat Med 2001, 7:186-191

11. Mandriota SJ, Jussila L, Jeltsch M, Compagni A, Baetens D, Prevo R, Banerji S, Huarte J, Montesano R, Jackson DG, Orci L, Alitalo K, Christofori G, Pepper MS: Vascular endothelial growth factor-C-mediated lymphangiogenesis promotes tumour metastasis. EMBO $J$ 2001, 20:672-682

12. Mattila MM, Ruohola JK, Karpanen T, Jackson DG, Alitalo K, Härkönen PL: VEGF-C induced lymphangiogenesis is associated with lymph node metastasis in orthotopic MCF-7 tumors. Int J Cancer 2002, 98:946-951

13. Jeon $B H$, Jang $C$, Han J, Kataru RP, Piao L, Jung $K$, Cha HJ, Schwendener RA, Jang KY, Kim KS, Alitalo K, Koh GY: Profound but dysfunctional lymphangiogenesis via vascular endothelial growth factor ligands from CD11b + macrophages in advanced ovarian cancer. Cancer Res 2008, 68:1100-1109

14. Kubota Y, Takubo K, Shimizu T, Ohno H, Kishi K, Shibuya M, Saya H, Suda T: M-CSF inhibition selectively targets pathological angiogenesis and lymphangiogenesis. J Exp Med 2009, 206:1089-1102

15. Schoppmann SF, Birner P, Stockl J, Kalt R, Ullrich R, Caucig C, Kriehuber E, Nagy K, Alitalo K, Kerjaschki D: Tumor-associated macrophages express lymphatic endothelial growth factors and are related to peritumoral lymphangiogenesis. Am J Pathol 2002, 161:947956

16. Schoppmann SF, Bayer G, Aumayr K, Taucher S, Geleff S, Rudas M, Kubista E, Hausmaninger H, Samonigg H, Gnant M, Jakesz R, Horvat R; Austrian Breast and Colorectal Cancer Study Group: Prognostic value of lymphangiogenesis and lymphovascular invasion in invasive breast cancer. Ann Surg 2004, 240:306-312

17. Gu Y, Qi X, Guo S: Lymphangiogenesis induced by VEGF-C and VEGF-D promotes metastasis and a poor outcome in breast carcinoma: a retrospective study of 61 cases. Clin Exp Metastasis 2008, 25:717-725

18. Nakamura Y, Yasuoka H, Tsujimoto M, Yang Q, Imabun S, Nakahara M, Nakao K, Nakamura M, Mori I, Kakudo K: Flt-4-positive vessel density correlates with vascular endothelial growth factor-d expression, nodal status, and prognosis in breast cancer. Clin Cancer Res 2003, 9:5313-5317

19. Nakamura Y, Yasuoka H, Tsujimoto M, Imabun S, Nakahara M, Nakao K, Nakamura M, Mori I, Kakudo K: Lymph vessel density correlates with nodal status. VEGF-C expression, and prognosis in breast cancer. Breast Cancer Res Treat 2005, 91:125-132

20. Karnezis T, Shayan R, Caesar C, Roufail S, Harris NC, Ardipradja K, Zhang Y-F, Williams SP, Farnsworth RH, Chai MG, Rupasinghe T, Tull D, Baldwin ME, Sloan EK, Fox SB, Achen MG, Stacker SA: VEGF-D promotes tumor metastasis by regulating prostaglandins produced by the collecting lymphatic endothelium. Cancer Cell 2012, 21:181195

21. Fisher B, Bauer M, Wickerham DL, Redmond CK, Fisher ER, Cruz AB, Foster R, Gardner B, Lerner H, Margolese R, Poisson R, Shibata H, Volk $\mathrm{H}$; other NSABP investigators. Relation of number of positive 
axillary nodes to the prognosis of patients with primary breast cancer. An NSABP update. Cancer 1983, 52:1551-1557

22. Achen MG, McColl BK, Stacker SA: Focus on lymphangiogenesis in tumor metastasis. Cancer Cell 2005, 7:121-127

23. Navarrete MA, Maier CM, Falzoni R, Quadros LG, Lima GR, Baracat EC, Nazário AC: Assessment of the proliferative, apoptotic and cellular renovation indices of the human mammary epithelium during the follicular and luteal phases of the menstrual cycle. Breast Cancer Res 2005, 7:R306-R313

24. Schedin P, Mitrenga T, Kaeck M: Estrous cycle regulation of mammary epithelial cell proliferation, differentiation, and death in the Sprague-Dawley rat: a model for investigating the role of estrous cycling in mammary carcinogenesis. J Mammary Gland Biol Neoplasia 2000, 5:211-225

25. Richert MM, Schwertfeger KL, Ryder JW, Anderson SM: An atlas of mouse mammary gland development. J Mammary Gland Biol Neoplasia 2000, 5:227-241

26. Watson CJ, Khaled WT: Mammary development in the embryo and adult: a journey of morphogenesis and commitment. Development 2008, 135:995-1003

27. Djonov V, Andres AC, Ziemiecki A: Vascular remodelling during the normal and malignant life cycle of the mammary gland. Microsc Res Tech 2001, 52:182-189

28. Matsumoto M, Nishinakagawa H, Kurohmaru M, Hayashi Y, Otsuka J: Pregnancy and lactation affect the microvasculature of the mammary gland in mice. J Vet Med Sci 1992, 54:937-943

29. Pepper MS, Baetens D, Mandriota SJ, Di Sanza C, Oikemus S, Lane TF, Soriano JV, Montesano R, Iruela-Arispe ML: Regulation of VEGF and VEGF receptor expression in the rodent mammary gland during pregnancy, lactation, and involution. Dev Dyn 2000, 218:507-524

30. Rossiter H, Barresi C, Ghannadan M, Gruber F, Mildner M, Födinger $D$, Tschachler E: Inactivation of VEGF in mammary gland epithelium severely compromises mammary gland development and function. FASEB J 2007, 21:3994-4004

31. Asselin-Labat ML, Sutherland KD, Barker H, Thomas R, Shackleton M, Forrest NC, Hartley L, Robb L, Grosveld FG, van der Wees J, Lindeman GJ, Visvader JE: Gata-3 is an essential regulator of mammary-gland morphogenesis and luminal-cell differentiation. Nat Cell Biol 2007, 9:201-209

32. Guy CT, Cardiff RD, Muller WJ: Induction of mammary tumors by expression of polyomavirus middle T oncogene: a transgenic mouse model for metastatic disease. Mol Cell Biol 1992, 12:954-961

33. Baldwin ME, Halford MM, Roufail S, Williams RA, Hibbs ML, Grail D, Kubo H, Stacker SA, Achen MG: Vascular endothelial growth factor D is dispensable for development of the lymphatic system. Mol Cell Biol 2005, 25:2441-2449

34. Gordon EJ, Gale NW, Harvey NL: Expression of the hyaluronan receptor LYVE-1 is not restricted to the lymphatic vasculature; LYVE-1 is also expressed on embryonic blood vessels. Dev Dyn 2008, 237: 1901-1909

35. Shackleton M, Vaillant F, Simpson KJ, Stingl J, Smyth GK, AsselinLabat ML, Wu L, Lindeman GJ, Visvader JE: Generation of a functional mammary gland from a single stem cell. Nature 2006, 439: $84-88$

36. Rozen S, Skaletsky H: Primer3 on the WWW for general users and for biologist programmers. Methods Mol Biol 2000, 132:365-386

37. Livak KJ, Schmittgen TD: Analysis of relative gene expression data using real-time quantitative PCR and the 2(-Delta Delta $\mathrm{C}(\mathrm{T})$ ) method Methods 2001, 25:402-408

38. Kazenwadel J, Michael MZ, Harvey NL: Prox1 expression is negatively regulated by miR-181 in endothelial cells. Blood 2010, 116 2395-2401

39. Kirkin V, Mazitschek R, Krishnan J, Steffen A, Waltenberger J, Pepper MS, Giannis A, Sleeman JP: Characterization of indolinones which preferentially inhibit VEGF-C- and VEGF-D-induced activation of VEGFR-3 rather than VEGFR-2. Eur J Biochem 2001, 268:5530-5540

40. Kirkin V, Thiele W, Baumann P, Mazitschek R, Rohde K, Fellbrich G, Weich $\mathrm{H}$, Waltenberger J, Giannis A, Sleeman JP: MAZ51, an indolinone that inhibits endothelial cell and tumor cell growth in vitro, suppresses tumor growth in vivo. Int J Cancer 2004, 112:986-993

41. Fong TA, Shawver LK, Sun L, Tang C, App H, Powell TJ, Kim YH, Schreck R, Wang X, Risau W, Ullrich A, Hirth KP, McMahon G SU5416 is a potent and selective inhibitor of the vascular endothelial growth factor receptor (Flk-1/KDR) that inhibits tyrosine kinase catal- ysis, tumor vascularization, and growth of multiple tumor types. Cancer Res 1999, 59:99-106

42. Kazenwadel J, Secker GA, Betterman KL, Harvey NL: In vitro assays using primary embryonic mouse lymphatic endothelial cells uncover key roles for FGFR1 signalling in lymphangiogenesis. PLoS One 2012, 7:e40497

43. Abràmoff MD, Magalhães PJ, Ram SJ: Image processing with ImageJ. Biophotonics Int 2004, 11:36-42

44. dela Paz NG, D'Amore PA: Arterial versus venous endothelial cells. Cell Tissue Res 2009, 335:5-16

45. Bazigou E, Xie S, Chen C, Weston A, Miura N, Sorokin L, Adams R, Muro AF, Sheppard D, Makinen T: Integrin-alpha9 is required for fibronectin matrix assembly during lymphatic valve morphogenesis. Dev Cell 2009, 17:175-186

46. Norrmén C, Ivanov KI, Cheng J, Zangger N, Delorenzi M, Jaquet M, Miura N, Puolakkainen P, Horsley V, Hu J, Augustin HG, Ylä-Herttuala S, Alitalo K, Petrova TV: FOXC2 controls formation and maturation of lymphatic collecting vessels through cooperation with NFATc1. J Cell Biol 2009, 185:439-457

47. Bazigou E, Lyons OT, Smith A, Venn GE, Cope C, Brown NA, Makinen $\mathrm{T}$ : Genes regulating lymphangiogenesis control venous valve formation and maintenance in mice. J Clin Invest 2011, 121:2984-2992

48. Srinivasan RS, Oliver G: Prox1 dosage controls the number of lymphatic endothelial cell progenitors and the formation of the lymphovenous valves. Genes Dev 2011, 25:2187-2197

49. Lin EY, Jones JG, Li P, Zhu L, Whitney KD, Muller WJ, Pollard JW: Progression to malignancy in the polyoma middle $T$ oncoprotein mouse breast cancer model provides a reliable model for human diseases. Am J Pathol 2003, 163:2113-2126

50. Fendrick JL, Raafat AM, Haslam SZ: Mammary gland growth and development from the postnatal period to postmenopause: ovarian steroid receptor ontogeny and regulation in the mouse. J Mammary Gland Biol Neoplasia 1998, 3:7-22

51. Hennighausen L, Robinson GW: Think globally, act locally: the making of a mouse mammary gland. Genes Dev 1998, 12:449-455

52. Parmar H, Cunha GR: Epithelial-stromal interactions in the mouse and human mammary gland in vivo. Endocr Relat Cancer 2004, 11:437458

53. Silberstein GB, Van Horn K, Shyamala G, Daniel CW: Essential role of endogenous estrogen in directly stimulating mammary growth demonstrated by implants containing pure antiestrogens. Endocrinology 1994, 134:84-90

54. Hennighausen L, Robinson GW: Information networks in the mammary gland. Nat Rev Mol Cell Biol 2005, 6:715-725

55. Lewis MP, Norman JT: Differential response of activated versus nonactivated renal fibroblasts to tubular epithelial cells: a model of initiation and progression of fibrosis? Exp Nephrol 1998, 6:132-143

56. Ohtani O, Shao XJ, Saitoh M, Ohtani Y: Lymphatics of the rat mammary gland during virgin, pregnant, lactating and post-weaning periods. Ital J Anat Embryol 1998, 103(4 Suppl 1):335-342

57. Marinho VF, Metze K, Sanches FS, Rocha GF, Gobbi H: Lymph vascular invasion in invasive mammary carcinomas identified by the endothelial lymphatic marker D2-40 is associated with other indicators of poor prognosis. BMC Cancer 2008, 8:64

58. Mohammed RA, Martin SG, Gill MS, Green AR, Paish EC, Ellis IO: Improved methods of detection of Iymphovascular invasion demonstrate that it is the predominant method of vascular invasion in breast cancer and has important clinical consequences. Am J Surg Pathol 2007, 31:1825-1833

59. Woo CS, Silberman H, Nakamura SK, Ye W, Sposto R, Colburn W, Waisman JR, Silverstein MJ: Lymph node status combined with lymphovascular invasion creates a more powerful tool for predicting outcome in patients with invasive breast cancer. Am J Surg 2002, 184:337-340

60. Albuquerque RJ, Hayashi T, Cho WG, Kleinman ME, Dridi S, Takeda A, Baffi JZ, Yamada K, Kaneko H, Green MG, Chappell J, Wilting J, Weich HA, Yamagami S, Amano S, Mizuki N, Alexander JS, Peterson ML, Brekken RA, Hirashima M, Capoor S, Usui T, Ambati BK, Ambat $\mathrm{J}$ : Alternatively spliced vascular endothelial growth factor receptor-2 is an essential endogenous inhibitor of lymphatic vessel growth. Nat Med 2009, 15:1023-1030

61. Koch M, Dettori D, Van Nuffelen A, Souffreau J, Marconcini L, Wallays G, Moons L, Bruyère F, Oliviero $S$, Noel A, Foidart JM, Carmeliet P Dewerchin M: VEGF-D deficiency in mice does not affect embryonic 
or postnatal lymphangiogenesis but reduces lymphatic metastasis. J Pathol 2009, 219:356-364

62. Achen MG, Jeltsch M, Kukk E, Makinen T, Vitali A, Wilks AF, Alitalo K, Stacker SA: Vascular endothelial growth factor D (VEGF-D) is a ligand for the tyrosine kinases VEGF receptor 2 (FIk1) and VEGF receptor 3 (Flt4). Proc Natl Acad Sci USA 1998, 95:548-553

63. Haiko P, Makinen T, Keskitalo S, Taipale J, Karkkainen MJ, Baldwin ME, Stacker SA, Achen MG, Alitalo K: Deletion of vascular endothelial growth factor C (VEGF-C) and VEGF-D is not equivalent to VEGF receptor 3 deletion in mouse embryos. Mol Cell Biol 2008, 28:48434850
64. Mohammed RA, Green A, El-Shikh S, Paish EC, Ellis IO, Martin SG: Prognostic significance of vascular endothelial cell growth factors $-A$, $-C$ and $-D$ in breast cancer and their relationship with angio- and lymphangiogenesis. Br J Cancer 2007, 96:1092-1100

65. Choi WW, Lewis MM, Lawson D, Yin-Goen Q, Birdsong GG, Cotsonis GA, Cohen C, Young AN: Angiogenic and lymphangiogenic microvessel density in breast carcinoma: correlation with clinicopathologic parameters and VEGF-family gene expression. Mod Pathol 2005, 18:143-152

66. Ran S, Volk L, Hall K, Flister MJ: Lymphangiogenesis and lymphatic metastasis in breast cancer. Pathophysiology 2010, 17:229-251 